\title{
Estradiol Enhances Leukocyte Binding to Tumor Necrosis Factor (TNF)-stimulated Endothelial Cells via an Increase in TNF-induced Adhesion Molecules E-Selectin, Intercellular Adhesion Molecule Type 1, and Vascular Cell Adhesion Molecule Type 1
}

\author{
Maria C. Cid, ${ }^{\star 8}$ Hynda K. Kleinman, ${ }^{\star}$ Derrick S. Grant, ${ }^{\star}$ H. William Schnaper, ${ }^{\star}$ Anthony S. Fauci, ${ }^{*}$ and Gary S. Hoffman ${ }^{\star}$ \\ * Laboratory of Immunoregulation, National Institute of Allergy and Infectious Diseases, and ${ }^{\ddagger}$ Laboratory of Developmental \\ Biology, National Institute of Dental Research, National Institutes of Health, Bethesda, Maryland 20892; and \\ ${ }^{\S}$ Department of Internal Medicine, Hospital Clinic i Provincial, 08036 Barcelona, Spain
}

\begin{abstract}
Adhesion of leukocytes to endothelial cells is a critical step in the development of acute and chronic inflammatory lesions. We report here that estradiol treatment of cultured human umbilical vein endothelial cells stimulated up to a twofold increase in TNF-induced adhesion of both polymorphonuclear leukocytes and PMA-activated peripheral blood mononuclear cells. This effect was more evident (threefold increase) when endothelial cells were cultured on the basement membrane glycoprotein laminin. Progesterone, but not testosterone, had a similar stimulatory effect. Estradiol also promoted a slight increase in interferon $\gamma$-stimulated endothelial cell adherence for peripheral blood mononuclear cells, but no effect of estradiol was observed when adhesion of leukocytes to endothelial cells was stimulated with IL-1 or IL-4. The estradiol-induced increase in leukocyte binding to human umbilical vein endothelial cells was partially blocked by antibodies to the adhesion molecules E-selectin, intercellular adhesion molecule type 1 ( ICAM-1), and vascular cell adhesion molecule type 1 ( VCAM-1). Indirect immunofluorescence techniques showed that estradiol produces an increase in TNF-induced cell surface expression of these molecules. Northern blot analysis demonstrated a transient increase in TNF-induced expression of mRNA for E-selectin, ICAM-1, and VCAM-1 in endothelial cells treated with estradiol. Our data demonstrate that estradiol has important regulatory functions in promoting leukocyte-endothelial cell interactions that might contribute to the observed predominance in females of some autoimmune inflammatory diseases. (J. Clin. Invest. 1994. 93:17-25.) Key words: estrogen • cytokines • endothelial cell $\cdot$ inflammation $\cdot$ vasculitis
\end{abstract}

\section{Introduction}

Sex hormones exert important regulatory functions in both normal and pathologic immune responses. This conviction is based on empirical observations in humans and in animal models $(1,2)$. For example, many chronic inflammatory and autoimmune diseases, particularly SLE (1-3) and Takayasu's ar-

Address correspondence to Dr. H. William Schnaper, Building 30, Room 407, National Institutes of Health, Bethesda, MD 20892. Gary S. Hoffman's present address is the Department of Rheumatic and Immunologic Disease. Cleveland Clinic, Foundation, 9500 Euclid Avenue, Cleveland, $\mathrm{OH} 44195$.

Received for publication 6 November 1992 and in revised form 4 June 1993.

The Journal of Clinical Investigation, Inc.

Volume 93, January 1994. 17-25 teritis (4), occur most often in women of child-bearing age. In SLE, the disease may be exacerbated by pregnancy or the use of oral contraceptives. In addition, studies of murine lupus in NZB/W mice have revealed that females have more severe disease than males. The role of gonadal steroids is further supported by evidence that outcome can be manipulated by castration and/or hormonal replacement $(1-3,5)$. The mechanisms through which sex hormones modulate the immune system are poorly understood. Based on the diversity of effects observed with in vivo models, gonadal steroids probably influence the biological behavior of a variety of cell types through different pathways $(1-3,6,7)$.

Interactions between leukocytes and endothelial cells have been recognized as critical to the development of acute and chronic inflammatory lesions. Infiltration of tissues by leukocytes depends upon their adhesion to endothelial cells and transmigration through the vessel wall $(8-10)$. Such interactions occur through specific receptor-ligand interactions. On the leukocyte membrane, lectin-like molecules (L-selectin), integrins (CD11-CD18 complex, VLA-4), immunoglobulin superfamily members (CD2, CD31), and carbohydrates (sialylated forms of Lewis antigen and others) bind to corresponding endothelial cell membrane ligands, including phospholipids (e.g., platelet-activating factor $\left.[\mathrm{PAF}]^{1}\right)(11)$, carbohydrates, lectin-like molecules (P-selectin, L-selectin), and immunoglobulin superfamily members (intercellular adhesion molecule type 1 [ ICAM-1] and -2, vascular cell adhesion molecule type 1 [VCAM-1], LFA-3, CD31) (8-10, 12). Some of these components are rapidly synthesized (PAF) or are translocated to the endothelial cell surface (P-selectin) after stimulation by a variety of substances, such as histamine or thrombin. Other receptors, including E-selectin, ICAM-1, and VCAM-1, appear later, require new protein synthesis, and are induced mainly by cytokines. These latter receptors are expressed by endothelial cells in chronic inflammatory lesions (13-16), including vasculitis (17).

Estrogen receptors have been demonstrated in cultured rabbit and bovine aortic endothelial cells $(18,19)$ and in fresh human aortic tissue (20). Progesterone receptors have been identified in the endothelium of human large vessels and in the contiguous adventitial microvasculature (21). Recently, estro-

1. Abbreviations used in this paper: DPBS, Dulbecco's PBS; HAEC, human aortic endothelial cells; HFEC, human fat tissue-derived endothelial cells; HUVEC, human umbilical vein endothelial cells; ICAM, intercellular adhesion molecule; IMEM, Iscove's MEM; M-199, Medium 199; PAF, platelet-activating factor; VCAM, vascular cell adhesion molecule; vWF Ag, von Willebrand factor antigen. 
gens have also been shown to elicit biological responses in various endothelial cells of different species $(19,22)$.

In this study, we have investigated the in vitro effect of sex steroids on leukocyte adhesion to endothelial cells and on cytokine-induced expression of endothelial cell adhesion molecules. Our results indicate that estrogens enhance leukocyte adhesion to the vascular wall through an increase in TNF-induced expression of adhesion molecules at the endothelial cell surface. This can be an important mechanism through which female sex hormones exacerbate the immune response.

\section{Methods}

Endothelial cell culture. Human umbilical vein endothelial cells (HUVEC) were obtained from fresh umbilical cords and cultured as previously described (23). Cells used for experiments were from passages four to eight. Human aortic endothelial cells (HAEC) were obtained from 8-cm fragments of necropsy specimens of human aorta kindly provided by the National Disease Research Interchange (NDRI; Philadelphia, PA). After removal of periaortic fat and connective tissue, the aortic segment was cut into $2-\mathrm{cm}^{2}$ pieces and incubated, endothelial side down, in $0.1 \%$ collagenase (Boehringer Mannheim Biochemicals, Indianapolis, IN) in Dulbecco's PBS (DPBS) without calcium and magnesium at $37^{\circ} \mathrm{C}$ for $20 \mathrm{~min}$. After incubation, the endothelium was scraped in Medium 199 (M-199; Gibco Laboratories, Grand Island, NY), collected, and centrifuged. The cell pellet was resuspended in the same growth medium used for HUVEC. The cells from each fragment were plated separately in six-well plates (Costar, Cambridge, MA) coated with $1 \%$ gelatin (Bio-Rad Laboratories, Richmond, CA). Smooth muscle cells or fibroblasts were identified by morphology and eliminated by cell scraping or by discarding overgrown cultures. After 3 wk, a confluent monolayer of a homogeneous cell population was obtained in which $>95 \%$ of the cells stained positively for von Willebrand factor antigen ( $v W F \mathrm{Ag}$ ) using indirect immunofluorescence with a polyclonal rabbit anti-human vWF Ag antibody (Dako Corp., Carpinteria, CA). Aortic endothelial cells were passed 1:4 every 2 wks and only passages four to six were used.

Human fat tissue-derived endothelial cells (HFEC) were obtained from retroperitoneal adipose tissue from the same necropsy specimen. The tissue was cut into $4-\mathrm{mm}^{2}$ pieces, incubated with $0.1 \%$ collagenase at $37^{\circ} \mathrm{C}$ for $30 \mathrm{~min}$, washed in DPBS, and pressed from the center towards the periphery to release endothelial cells. The primary culture was grown on M-199 with D-valine instead of L-valine to inhibit fibroblast growth. The rest of the procedure was essentially the same as that for HAEC.

Leukocyte isolation. PMN and PBMC were obtained from healthy donors and were purified by gradient centrifugation on mono-poly resolving medium (Flow Laboratories, McLean, VA) as described (24). This procedure yielded a $95 \%$ effective separation as determined by the presence of peroxidase activity in the PMN, and $>95 \%$ cell viability as determined by trypan blue exclusion.

Leukocyte-endothelial cell adhesion assay. 48-well plates (Costar) were coated with $1 \%$ gelatin or $0.1 \mathrm{mg} / \mathrm{ml}$ laminin (25). HUVEC, HAEC, or HFEC were suspended in phenol red-free Iscove's MEM (IMEM) (Biofluids, Rockville, MD) supplemented with the same reagents as the growth medium, except $10 \%$ calf serum treated with charcoal to remove steroid hormones was used (kindly provided by Erik Thompson, Lombardi Cancer Center, Washington, DC). The cells were plated at a density of $10^{5} /$ well and allowed to form confluent monolayers overnight. The conditioned medium was aspirated and replaced by phenol red-free IMEM supplemented with insulin, transferrin, and selenium ( $\mathrm{ITS}^{+}$) (Collaborative Research) under serumfree conditions, and the following reagents, alone or in combination, were added: recombinant human TNF $\alpha$, recombinant human IL-1 $\alpha$, recombinant human IL-4, recombinant human IFN- $\gamma$ (Genzyme, Boston, MA), 17- $\beta$ estradiol, progesterone, or testosterone (Sigma Chemical Co., St. Louis, MO). Steroid hormones were used at concentrations ranging from 0.5 to $5 \mathrm{ng} / \mathrm{ml}$ (usual plasma concentrations are
$0.5-2 \mathrm{ng} / \mathrm{ml}$, with values $>30 \mathrm{ng} / \mathrm{ml}$ often found in pregnancy). TNF $\alpha$ was used at $200 \mathrm{U} / \mathrm{ml}$, and IL- $1 \alpha$ at $30 \mathrm{U} / \mathrm{ml}$ based on preliminary experiments demonstrating that these concentrations were the minimum required to stimulate optimal adhesion in our system. In the dose ranges noted, each cytokine induced a comparable response in leukocyte adhesion. In some experiments, IL-4 at $200 \mathrm{U} / \mathrm{ml}$ or IFN- $\gamma$ at $500 \mathrm{U} / \mathrm{ml}$ were used to stimulate adhesion to PBMC. After various incubation times (3-24 h), the conditioned medium was aspirated, and either PMN or PBMC $\left(2.5-5 \times 10^{5} /\right.$ well $)$ in hormone-free medium were added. In some experiments, $\mathrm{PBMC}$ were previously stimulated with $100 \mathrm{nM}$ PMA (Sigma Chemical Co.) for $1 \mathrm{~h}$ at $37^{\circ} \mathrm{C}$. After a 30-min incubation for PMN and 40-60 min for PBMC, the leukocytecontaining medium was removed by aspiration, and the endothelial cell monolayers were washed once with unsupplemented medium prewarmed at $37^{\circ} \mathrm{C}$. The cultures were then fixed and stained with DiffQuik (Baxter Healthcare Corporation, McGaw Park, IL). PMN were fixed in $3.7 \%$ formaldehyde in M-199 for $15 \mathrm{~min}$, washed once with TBS, and incubated with $0.06 \%$ chloro-naphthol (Aldrich Chem. Co., Milwakee, WI) in $10 \%$ methanol in TBS with $0.06 \% \mathrm{H}_{2} \mathrm{O}_{2}$ for 2-3 min until, because of their endogenous peroxidase activity, they became dark blue. An additional wash with distilled water was then performed. Adherent PMN were easily distinguishable from the unstained underlying endothelial cell monolayer, and the mean PMN area/well in 10 fields covering the entire well surface was measured with a computerized digital analyzer (Optomax, Burlington, MA). Adherent PBMC stained darker than the underlying endothelium and were measured by visual counting. Each condition was evaluated in triplicate wells and results are expressed as the percent increase over control. Each experiment was repeated three times and one representative experiment is shown.

Inhibition of leukocyte-endothelial cell interactions by antiadhesion molecule antibodies. HUVEC were incubated with TNF $\alpha(200$ $\mathrm{U} / \mathrm{ml}$ ), with or without $17-\beta$ estradiol for $6 \mathrm{~h}$ as described above. Then, antibodies $(10 \mu \mathrm{g} / \mathrm{ml})$ were added and adhesion assays for PMN and for PMA-activated PBMC were performed as described above. The antibodies used were mouse monoclonal antibody RR1/1, which recognizes ICAM-1 (kindly provided by Timothy Springer, Harvard University, Boston, MA), mouse monoclonal antibody 4B9, which recognizes VCAM-1, and rabbit anti-human E-selectin polyclonal antibody (both generous gifts from Roy Lobb, Biogen Inc, Cambridge, MA).

Immunofluorescence detection of cell surface receptors. Subconfluent HUVEC (10,000/well) were plated on either $1 \%$ gelatin- (BioRad Laboratories) or $0.1 \mathrm{mg} / \mathrm{ml}$ laminin-coated eight-chamber glass slides (Nunc, Roskilde, Denmark), and cultured overnight in phenol red-free IMEM with $10 \%$ charcoal-treated calf serum. HUVEC were stimulated with the above-mentioned cytokines and $17-\beta$ estradiol at 5 $\mathrm{ng} / \mathrm{ml}$ for 6-8 h. Cells were fixed with 3.7\% formaldehyde in M-199 for $15 \mathrm{~min}$, and cell surface receptor expression was evaluated by indirect immunofluorescence using either mouse monoclonal antibody $\mathrm{H} 18$ / 7, which recognizes E-selectin (kindly provided by Michael Gimbrone, Jr., Harvard University), or the above-described RR1 / 1 and 4B9 antibodies (concentration, $10 \mu \mathrm{g} / \mathrm{ml}$ ). The secondary antibody, FITCconjugated goat anti-mouse purified IgG (Cappel Laboratories, West Chester, PA) was diluted 1:200. Slides were mounted with $2.5 \% n$-propyl gallate in $50 \%$ glycerol in PBS. Immunostaining was performed three times with similar results.

In parallel experiments, HUVEC cultured under the same conditions were released with Versene (Gibco Laboratories), pelleted, and resuspended in wash buffer ( $2 \% \mathrm{FCS}, 0.1 \% \mathrm{NaN}_{3}$ in PBS) and adjusted to $10^{6} / \mathrm{ml}$. Aliquots were incubated for $30 \mathrm{~min}$ at $4^{\circ} \mathrm{C}$ with the monoclonal antibodies 4B9 (anti-VCAM-1) at $10 \mu \mathrm{g} / \mathrm{ml}$ or RM 3A5 (antiICAM-1) used as hybridoma supernate diluted $1: 2$, or a polyclonal rabbit anti-human antibody at $10 \mu \mathrm{g} / \mathrm{ml}$. After two washes at $4^{\circ} \mathrm{C}$, the cells were incubated with fluorescein-conjugated goat anti-mouse IgG or goat anti-rabbit IgG (Cappel Laboratories) at a 1:200 dilution. HUVEC were then subjected to flow cytometry (FACStar Plus ${ }^{\oplus}$; Becton Dickinson Immunocytochemistry Systems, San Jose, CA). Changes in antigen expression by estrogen-treated cells were felt to be significant 
when there was a $99 \%$ confidence level that the histograms from treated and untreated cells were distinct, as determined through KolmogorovSmirnov analysis (26).

Northern blot analysis. HUVEC or HAEC were plated at confluence on $0.1 \mathrm{mg} / \mathrm{ml}$ laminin and incubated for either $1,3,4,8$, or 24 $\mathrm{h}$ with either TNF $\alpha$ alone $(200 \mathrm{U} / \mathrm{ml})$ or in combination with $17-\beta$ estradiol $(5 \mathrm{ng} / \mathrm{ml})$ as described above. In some experiments, actinomycin D at $2 \mu \mathrm{g} / \mathrm{ml}$ was added after a 2-h incubation. Total RNA was obtained from cells in each condition by guanidine-isothiocyanate lysis and centrifugation over a cesium chloride cushion (27). $10 \mu \mathrm{g}$ of total RNA per lane was loaded on a $1 \%$ agarose-formaldehyde gel, subjected to electrophoresis, blotted onto nylon-supported nitrocellulose filters ( Nytran; Schleicher \& Schuell, Inc., Keene, NH), and UV crosslinked to the filter. A cDNA probe for ICAM-1 (kindly provided by Timothy Springer, Harvard University) was labeled with $\left[{ }^{32} \mathrm{P}\right] \mathrm{dCTP}$ (ICN Biomedicals, Costa Mesa, CA) with a random priming kit (Boehringer Mannheim Biochemicals). In addition, a mixture of synthetic 30-mer oligonucleotides antisense for either E-selectin or VCAM-1 cDNA sequence ( $R$ \& D Systems, Minneapolis MN) was ${ }^{32} \mathrm{P} 5$ ' end-labeled by the T4 kinase (Boehringer Mannheim Biochemicals) forward reaction (28). Filters were hybridized, washed under the required conditions of stringency, and autoradiographed at $-70^{\circ} \mathrm{C}$. Each condition was evaluated three times with RNA samples obtained in three different experiments. To correct blotting signals for loading and normalize results, filters were also hybridized with a cDNA for $28 \mathrm{~s}$ ribosomal RNA, provided by Helene Sage (University of Washington, Seattle, WA).

\section{Results}

Effect of sex hormones on leukocyte adhesion to HUVEC. Incubation of HUVEC with either 17- $\beta$ estradiol, progesterone, or testosterone did not result in any increase above background leukocyte adhesion to the endothelial cell monolayers (data not shown). In contrast, incubation of TNF-stimulated HUVEC with 17- $\beta$ estradiol resulted in a two- to threefold increase in adhesion to PMN above the binding achieved with optimal doses of TNF alone (Figs. 1 and 2). The increase in PMN binding was estradiol dose dependent, was optimal at 2-5 ng/ $\mathrm{ml}$ (Figs. 1 and $2 A$ ), and decreased at higher concentrations (data not shown). PMN binding reached a maximum at $\sim 6 \mathrm{~h}$ and decreased subsequently (Fig. $2 \mathrm{~B}$ ). In contrast to PMN, unstimulated PBMC adhered poorly to either IL-1-, IL-4-,
IFN- $\gamma-$, or TNF-stimulated HUVEC, and such adhesion was not further increased by estradiol (data not shown). PMA-activated PBMC did bind to TNF-stimulated HUVEC, and this effect was also enhanced by estradiol (Fig. 2). Enhanced adhesion of PMA-treated PBMC by estradiol occurred later, was more sustained, and was generally less intense than that achieved for PMN (Fig. 2). When the effect of estradiol in stimulating the adhesion induced by other cytokines was tested, no significant effect was observed on IL-1-induced adherence for either PMN or PBMC, or in IL-4-induced adhesion for PBMC (Fig. 3). Conversely, estradiol slightly potentiated the effect of IFN- $\gamma$ in promoting PBMC adhesion.

Extracellular matrix modulated the HUVEC response to estradiol in the presence of TNF since the estradiol-induced increase in adhesion of PMN was further enhanced (three- vs. twofold increase) when HUVEC were plated on the basement membrane glycoprotein laminin than when the cells were plated on plastic (not shown) or gelatin (Fig. 4). When other sex hormones were tested in the same system and in the same range of concentrations, progesterone but not testosterone showed a comparable effect (Fig. 5).

Effect of 17- $\beta$ estradiol on PMN adhesion to TNF-stimulated HAEC and HFEC. Since endothelial cells from different tissues show different biological properties, we explored the ability of other endothelial cell types to respond to estradiol in our system. PMN adhesion to TNF-treated HFEC and HAEC in the presence or absence of estradiol was tested at the aforementioned range of concentrations. Estradiol also increased TNF-induced leukocyte adhesion to HAEC. In addition, the maximal effect of estradiol on HAEC was achieved at a lower concentration $(1 \mathrm{ng} / \mathrm{ml})$ as compared with $2-5 \mathrm{ng} / \mathrm{ml}$ for HUVEC. In contrast, HFEC showed only a slight response (Table I).

Effect of antiadhesion molecule antibodies on estrogen-induced endothelial cell-leukocyte adhesion. To assess whether the effect of estradiol occurs through modulation of TNF-induced adhesion molecules, we examined whether blocking antibodies against cytokine-induced endothelial adhesion molecules E-selectin, ICAM-1, and VCAM-1 would reduce estra-
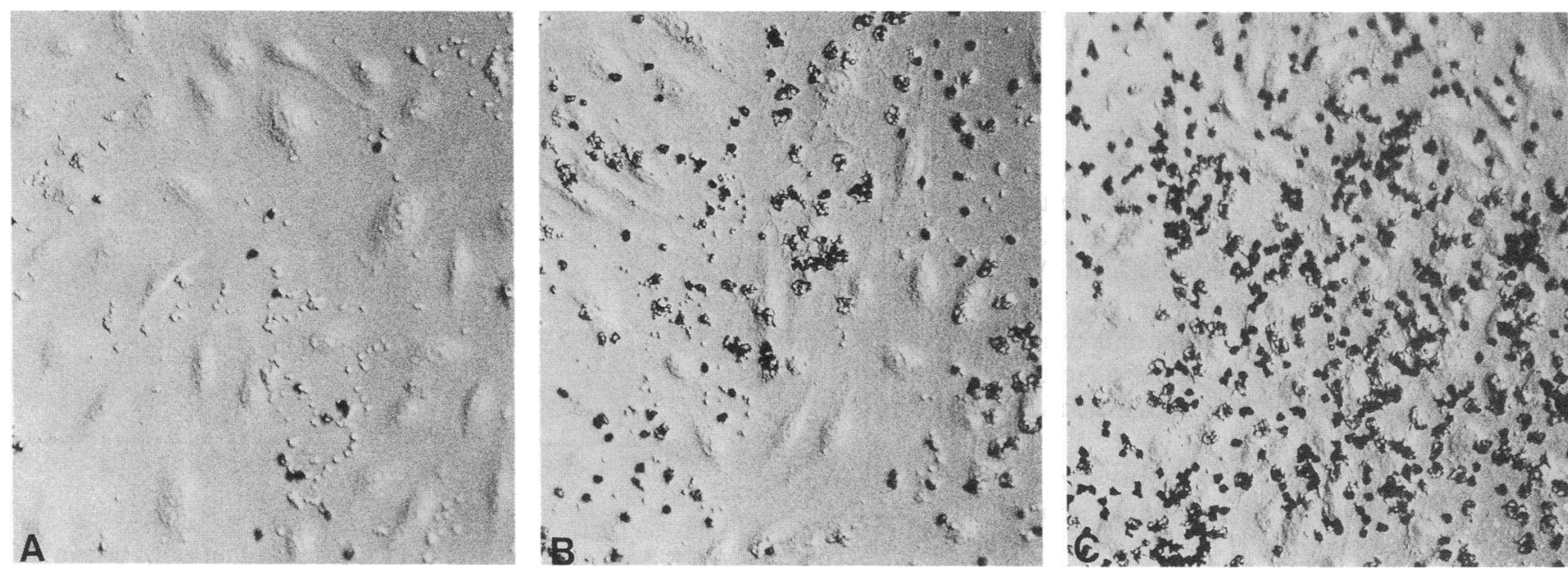

Figure 1. Adhesion of PMN to endothelial cells. Resting HUVEC $(A)$, TNF-stimulated HUVEC $(B)$, and HUVEC exposed to TNF and estradiol $(C)$. HUVEC were plated on laminin and treated for $6 \mathrm{~h}$ with TNF $\alpha(200 \mathrm{U} / \mathrm{ml})$ in the absence or presence of $5 \mathrm{ng} / \mathrm{ml} \mathrm{of} 17-\beta$ estradiol. Peroxidase activity in PMN turns them dark and makes them easily distinguishable from the underlying endothelium. Hoffman modulation contrast $(\times 175)$. 

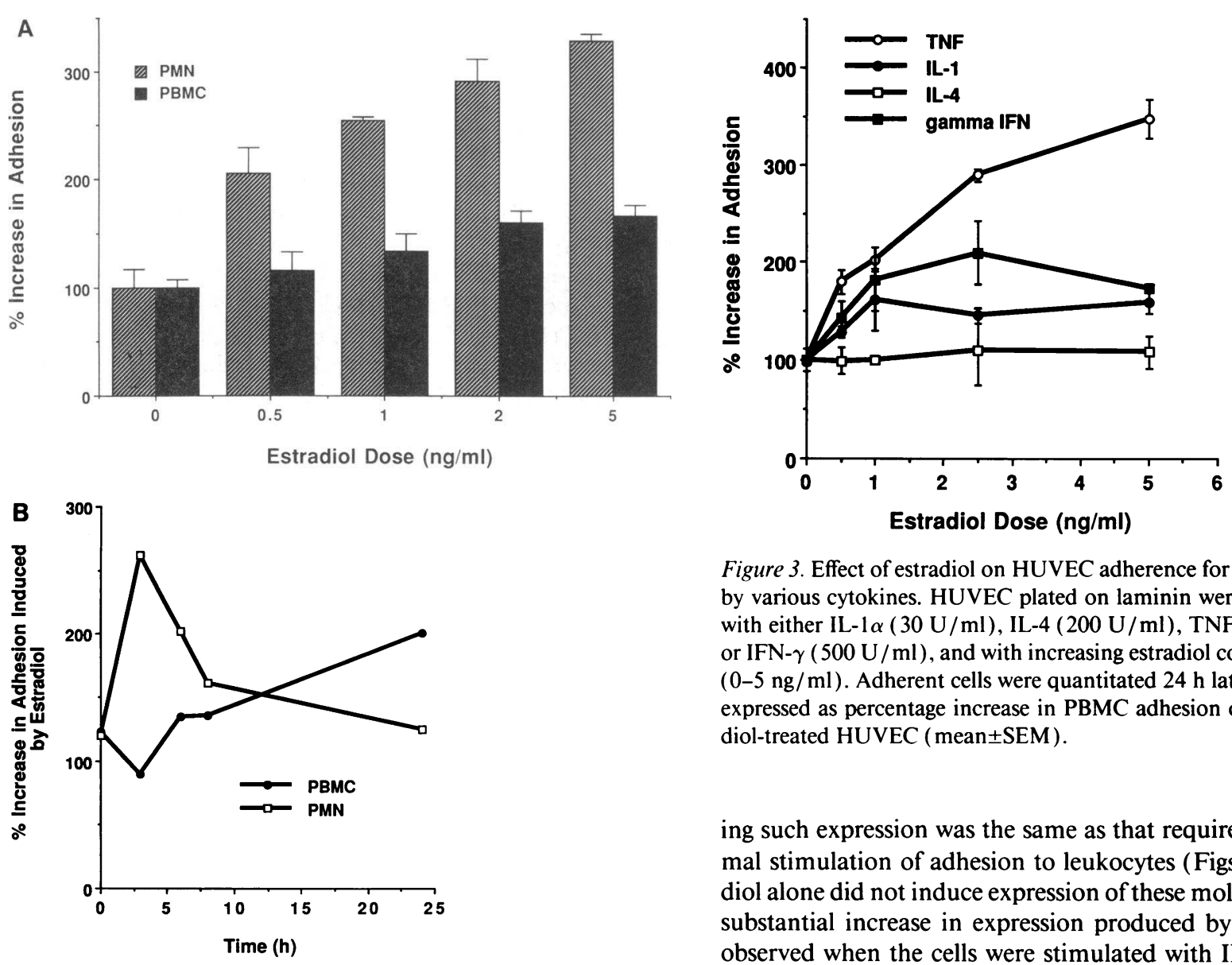

Figure 2. $(A)$ Effect of increasing concentrations of estradiol on adhesion of PMN or PMA-stimulated PBMC to TNF-stimulated HUVEC. HUVEC were cultured on laminin, and treated for $6 \mathrm{~h}$ with $\mathrm{TNF} \alpha(200 \mathrm{U} / \mathrm{ml})$ and $17-\beta$ estradiol at $0-5 \mathrm{ng} / \mathrm{ml}$. Bars represent percentage increase (mean \pm SD of triplicate wells) in adhesion to estradiol-treated HUVEC at different concentrations vs. estradiol nontreated endothelium. $(B)$ Kinetics of estradiol-induced increase in TNF-stimulated adherence of HUVEC for PMN or PBMC. HUVEC plated on laminin were stimulated with TNF $(200 \mathrm{U} / \mathrm{m})$ with or without $17-\beta$ estradiol $(2.5 \mathrm{ng} / \mathrm{ml})$ for $3,6,8$, and $24 \mathrm{~h}$. Results are expressed as percentage increase in PMN or PBMC adhesion in estradiol-treated cells vs. the corresponding condition without estradiol at each time-point.

diol-increased adhesion. Anti-E-selectin and anti-ICAM-1 diminished the increase in PMN binding to TNF-stimulated HUVEC induced by estradiol, whereas anti-VCAM-1 was without significant effect. For PBMC, anti-VCAM-1 and antiICAM-1, but not anti-E-selectin, partially blocked estradiol-increased adhesion (Table II). These data confirm that the PMN and PBMC recognize different adhesion receptors on the endothelial cells, and that each binding mechanism is modulated by estradiol.

Effect of 17- $\beta$ estradiol on surface expression of adhesion receptors. Using indirect immunofluorescence, an increase in the surface expression of TNF-induced E-selectin, ICAM-1, and VCAM-1 was observed in estradiol-treated cells (Fig. 6). This effect was dose dependent and was more prominent when the cells were plated on laminin rather than on plastic (data not shown $)$. The optimal estradiol dose $(2.5-5 \mathrm{ng} / \mathrm{ml})$ for enhanc-

Figure 3. Effect of estradiol on HUVEC adherence for PBMC induced by various cytokines. HUVEC plated on laminin were stimulated with either IL-1 $\alpha(30 \mathrm{U} / \mathrm{ml}), \mathrm{IL}-4(200 \mathrm{U} / \mathrm{ml}), \mathrm{TNF} \alpha(200 \mathrm{U} / \mathrm{ml})$, or IFN- $\gamma(500 \mathrm{U} / \mathrm{ml})$, and with increasing estradiol concentrations $(0-5 \mathrm{ng} / \mathrm{ml})$. Adherent cells were quantitated $24 \mathrm{~h}$ later. Results are expressed as percentage increase in PBMC adhesion over non-estradiol-treated HUVEC ( mean \pm SEM).

ing such expression was the same as that required for an optimal stimulation of adhesion to leukocytes (Figs. 2-5). Estradiol alone did not induce expression of these molecules, and no substantial increase in expression produced by estradiol was observed when the cells were stimulated with IL-1 instead of TNF (data not shown).

Flow cytometry of HUVEC in suspension was performed to evaluate the effect of estradiol on TNF-induced expression of adhesion molecules at different time points. As shown in Fig. 7, estradiol enhanced E-selectin expression early, at $3 \mathrm{~h}$, whereas at later time-points estradiol predominantly enhanced VCAM-1 surface expression. Changes in expression of ICAM were equivocal by this technique.

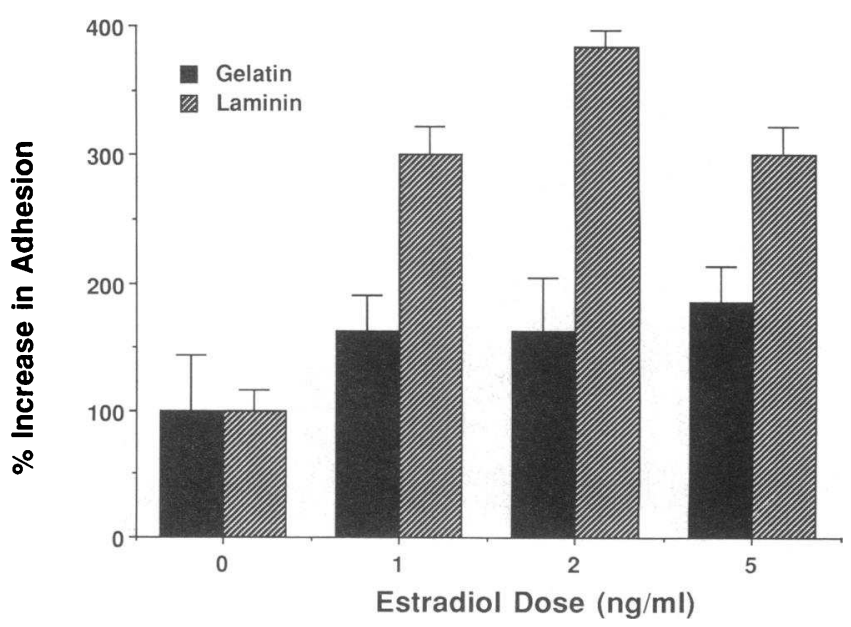

Figure 4. Adherence of PMN to HUVEC plated on either gelatin or laminin in the presence of estradiol. Results are expressed as percentage increase in adhesion to estradiol-treated $\operatorname{HUVEC}(1-5 \mathrm{ng} / \mathrm{ml})$ compared with adhesion to untreated HUVEC. Bars represent mean $\pm \mathrm{SD}$ of triplicate wells. 


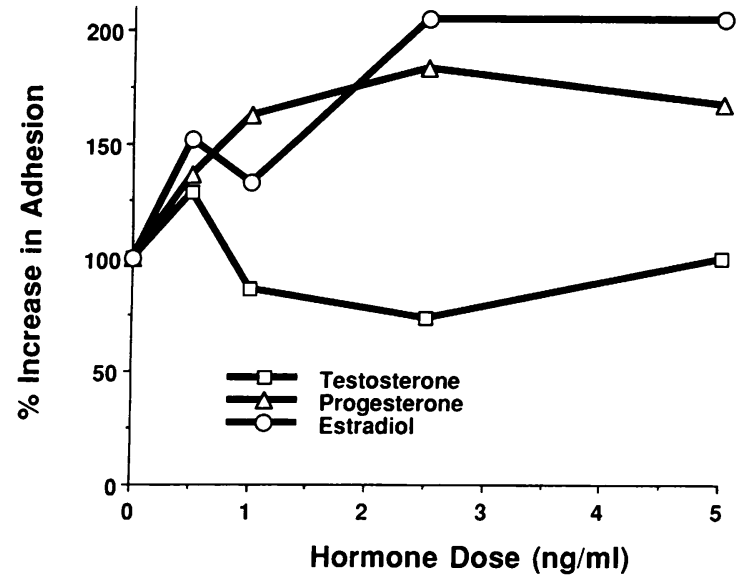

Figure 5. Comparative effect of 17- $\beta$ estradiol, progesterone, and testosterone on PMN adhesion to TNF-stimulated HUVEC. Results are expressed as percentage increase in adhesion to TNF-stimulated HUVEC in the absence of steroids (mean of duplicate wells).

Effect of estradiol on E selectin, ICAM-1, and VCAM-1 $m R N A$ levels. Estradiol alone did not increase mRNA expression for any of the adhesion molecules (data not shown). In the presence of TNF, however, estradiol treatment of HUVEC resulted in a 30-50\% increase in expression of mRNA for E-selectin, ICAM-1, and VCAM-1 by $4 \mathrm{~h}$ (Fig. 8). At $6 \mathrm{~h}$, the relative signal intensities in the presence and absence of estradiol were reversed, with more signal present without estradiol for each of the three adhesion molecules (Fig. 8). At $24 \mathrm{~h}$, the amount of mRNA was similar in estradiol-treated or -untreated cells (data not shown). Since plating HUVEC on laminin increased binding of leukocytes to the endothelial cell monolayer, we evaluated mRNA expression comparing cells on plastic or on laminin. As shown in Fig. 9, the estrogen-stimulated increase in steady-state mRNA expression for adhesion molecules was greater on laminin $(50-75 \%)$. The later, estradiol-induced decrease in mRNA levels for adhesion molecules was accelerated by treating the cells with actinomycin D. With cells on laminin, the decrease after treatment with actinomycin D was less apparent (Fig. 9). These findings indicate that the estradiol-induced increase in steady-state expression of

Table I. Effect of Estradiol on TNF-induced PMN Adhesion to Different Endothelial Cell Types

\begin{tabular}{lcccc}
\hline & \multicolumn{5}{c}{ Estradiol dose $(\mathrm{ng} / \mathrm{ml})$} \\
\cline { 2 - 5 } Endothelial cell type & 0 & 0.5 & 1 & 2.5 \\
\hline & & \multicolumn{4}{c}{$\%$} \\
HUVEC & 100 & 125 & 172 & 199 \\
HAEC & 100 & 135 & 192 & 184 \\
HFEC & 100 & 122 & 123 & 106 \\
& & & & \\
\hline
\end{tabular}

Endothelial cell monolayers from HUVEC, HAEC, and HFEC were stimulated for $5 \mathrm{~h}$ with TNF $(200 \mathrm{U} / \mathrm{ml})$ and increasing concentrations of $17-\beta$ estradiol before being overlaid with PMN for $1 \mathrm{~h}$. Adherent cells were enumerated as described in Methods. Results are expressed as percentage increase over the adhesion obtained with TNF alone (mean of duplicate wells). Data are from one experiment representative of three similar experiments.
Table II. Effect of Anti-E-selectin, ICAM-1, and VCAM-1 Antibodies on Estradiol-enhanced Leukocyte Binding to TNF-stimulated HUVEC

\begin{tabular}{|c|c|c|c|c|c|c|}
\hline \multirow[b]{2}{*}{ Antibody } & \multicolumn{3}{|c|}{ PMN } & \multicolumn{3}{|c|}{ PBMC } \\
\hline & $0^{*}$ & 0.2 & 1 & $0^{*}$ & 0.2 & 1 \\
\hline & \multicolumn{6}{|c|}{$\%$} \\
\hline None & 100 & 134 & 149 & 100 & 125 & 150 \\
\hline 4B9 (VCAM-1) & 100 & 134 & 160 & 100 & 110 & 95 \\
\hline Anti-E-selectin & 100 & 85 & 120 & 100 & 123 & 152 \\
\hline RR1/1 (ICAM-1) & 100 & 85 & 97 & 100 & 92 & 105 \\
\hline
\end{tabular}

HUVEC were stimulated with TNF $(200 \mathrm{U} / \mathrm{ml})$ in the absence or in the presence of 17- $\beta$ estradiol for $4 \mathrm{~h}$. Then, the above-mentioned antibodies were added at $10 \mu \mathrm{g} / \mathrm{ml}$. After an additional $1 \mathrm{~h}$, the medium was aspirated and leukocytes in fresh medium were layered onto the endothelial monolayer. Adherent cells were counted $1 \mathrm{~h}$ later as described in Methods. Results are expressed as percentage increase over the adhesion obtained on HUVEC without estradiol in the presence of each antibody (mean of duplicate wells). ${ }^{*}$ Estradiol dose (ng/ml).

mRNA for adhesion molecules is transient and peaks before the time at which increased protein expression was noted by immunofluorescence.

\section{Discussion}

In this study, we demonstrated that estradiol increases TNF-induced adhesiveness of endothelial cells for leukocytes via increased expression of the endothelial adhesion molecules E-selectin, ICAM-1, and VCAM-1. The kinetics of estradiol-enhanced adhesion were different for PMN and for PBMC, with PMN binding being maximal at early time points and PBMC binding being at $24 \mathrm{~h}$. During the first hours, flow cytometry demonstrated a preferential effect of estradiol in increasing expression of E-selectin, which mainly binds PMN. In contrast, at $24 \mathrm{~h}$, estradiol-stimulated expression of VCAM-1, which preferentially mediates PBMC binding, was more evident. This pattern closely follows the kinetics of TNF-stimulated binding and induction of adhesion molecules reported by others $(9,10$, 29,30 ), with the effect amplified by estradiol.

The maximum increase in adhesion promoted by estradiol was generally greater for PMN than for PBMC. Other studies have shown that, even at optimal times for each cell type, TNFinduced adhesiveness of endothelial cells is higher for PMN than for lymphocytes (31). In addition, in this study, estradiol did not increase TNF-induced binding to PBMC unless the PBMC were stimulated with PMA. The affinity of integrin receptors on resting lymphocytes for their ligands on cytokinestimulated endothelial cells is low, but this affinity increases dramatically after lymphocyte activation by a variety of stimuli, including PMA (32-35). In contrast, when PMN contact activated endothelial cells, a cascade triggered by interactions through selectins $E$ and P, PAF, and IL-8 induces further binding without requiring exogenous agents to activate the PMN $(11,36)$. The adhesion patterns observed in the present series of experiments suggest that estradiol upregulates endothelial expression of ligands for leukocyte integrins, and enhances en- 

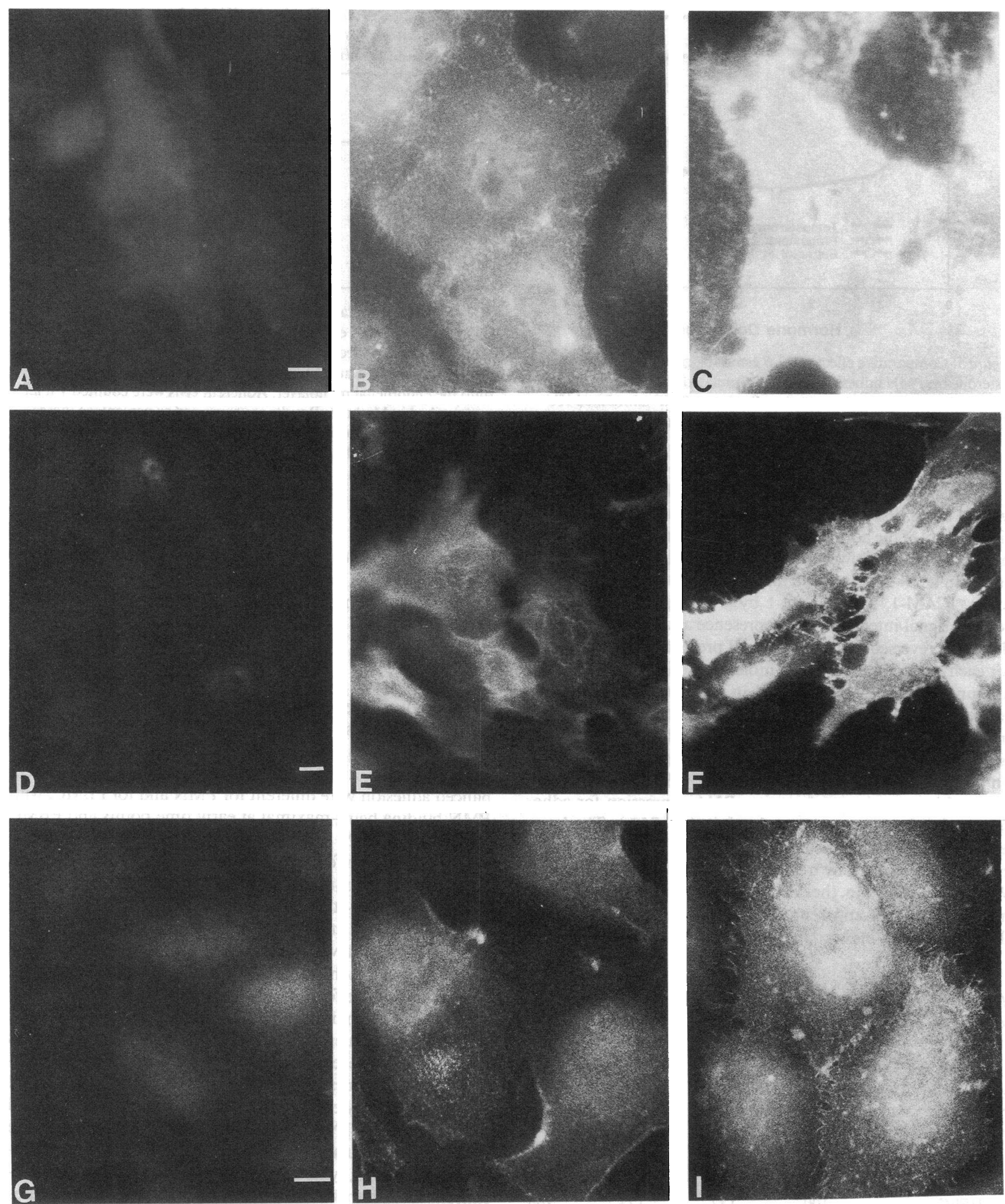

Figure 6. Indirect immunofluorescence of cultured HUVEC on laminin. $A, D$, and $G$ correspond to resting HUVEC; $B, E$, and $H$ to TNF-stimulated HUVEC; and $C, F$, and $I$ to TNF stimulated HUVEC with $5 \mathrm{ng} / \mathrm{ml}$ estradiol. $A, B$, and $C$ were incubated with a rabbit polyclonal antiE-selectin antibody; $D, E$, and $F$ with RR $1 / 1$ (anti-ICAM-1) monoclonal antibody, and $G, H$, and $I$ with 4B9 (anti-VCAM-1) monoclonal antibody. Pictures were taken with identical exposure times. Bar $=10 \mu \mathrm{m}$. 


\section{E-selectin}
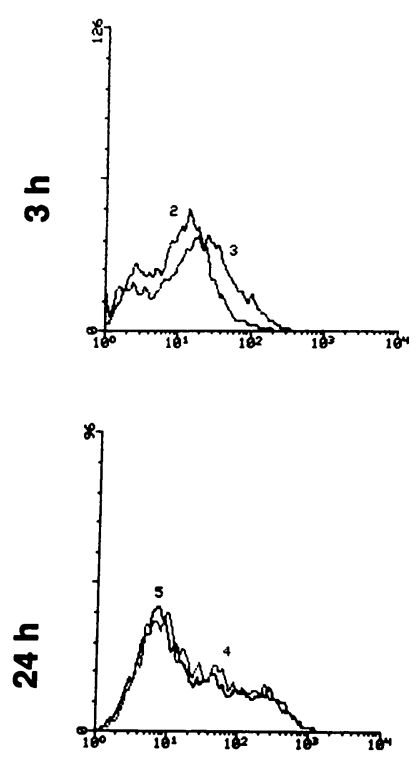

ICAM-1
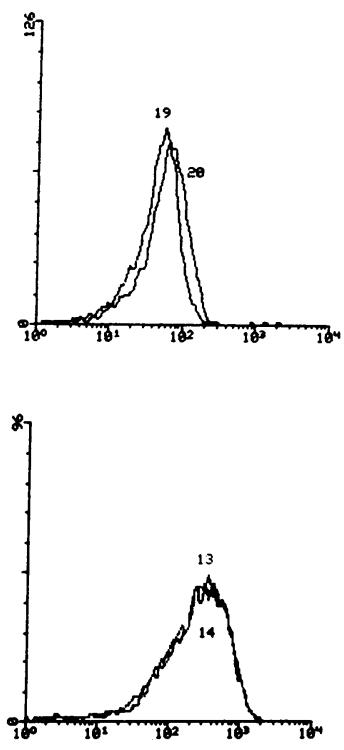

dothelial-leukocyte interactions, at least in part, via a mechanism that is independent of effects on leukocytes.

The effect of estradiol in our system was dependent upon TNF, since estradiol alone had no effect on leukocyte adhesion to endothelial monolayers. Recently, sex hormones have been shown to interact with cytokines in several cell systems. These interactions include both regulation of cytokine production by gonadal steroids (37-41) and regulation of steroid production and response to sex hormones by cytokines $(42,43)$. Surprisingly, no effect of estradiol was observed on IL-1-induced adhesion for leukocytes even though the pattern of endothelial cell activation induced by this cytokine closely parallels TNF effects (44). This observation suggests that the mechanisms of TNF- and IL-1-induced adhesion are distinct, and it agrees with previous reports by others suggesting that regulation of adhesion molecule expression by these two cytokines occurs through distinct mechanisms. TNF but not IL-1 is synergistic with IL-4 and IFN- $\gamma$ in stimulating endothelial cell adhesion to
VCAM-1

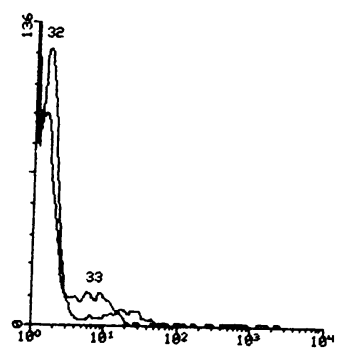

Figure 7. Flow cytometry of HUVEC in suspension. HUVEC cultured on laminin were incubated for $3 \mathrm{~h}$ (top) or for $24 \mathrm{~h}$ (bottom) with $\mathrm{TNF} \alpha(200 \mathrm{U} / \mathrm{ml})$ with or without estradiol at $5 \mathrm{ng} / \mathrm{ml}$. Cells were nonenzymatically released, subjected to indirect immunofluorescence with anti-E-selectin, anti ICAM-1, and anti-VCAM-1, and fluorescence intensity was measured by flow cytometry. In the graph for E-selectin at $3 \mathrm{~h}$ (top left) and for V-CAM-1 at $24 \mathrm{~h}$, estradiol induces a rightward shift of the curve.

lymphocytes $(45,46)$. On the other hand, dexamethasone downregulates E-selectin and ICAM-1 expression induced by LPS or IL-1 but not by TNF (47). These reports are consistent with our findings, where estradiol slightly increased PBMC adhesion induced by IFN- $\gamma$ and no enhanced PBMC adhesion was seen when estradiol was added to IL-4-stimulated HUVEC.

In addition to HUVEC, we investigated the ability of other endothelial cell types to respond to estradiol. Among the three cell types tested, HAEC showed the highest response to estradiol in promoting TNF-induced leukocyte adhesion. This may reflect the greater density of gonadal steroid receptors in large vessels (18-21, 48). Estradiol enhancement of leukocyte adhesion to large artery endothelial cells might play a role in the strong female gender predominance observed in Takayasu's arteritis, which involves mainly the aorta and its major branches (4).

Estradiol produced an increase in surface expression of TNFinduced endothelial adhesion molecules E-selectin, ICAM-1,

E-selectin

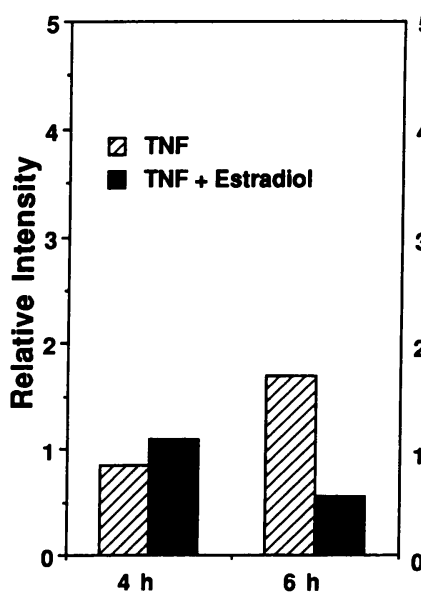

$4 \mathrm{~h}$
ICAM-1

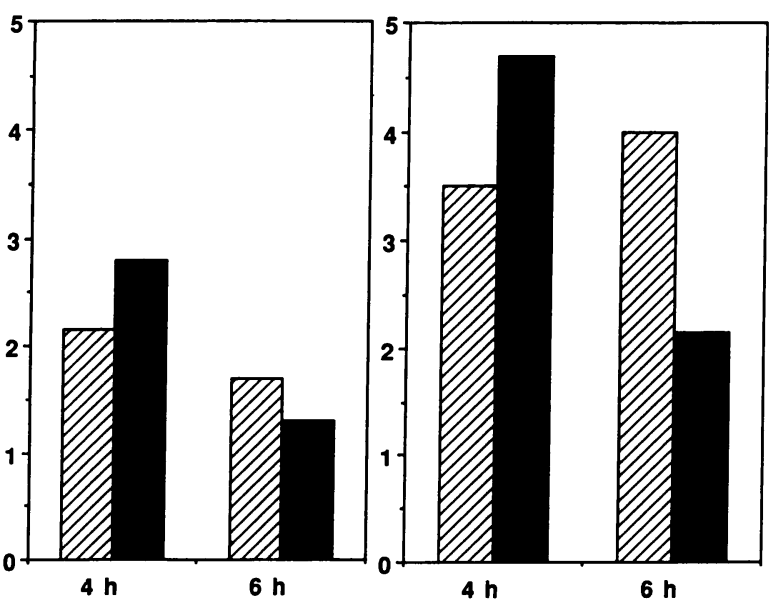

Time

Figure 8. Quantitative measurement of the mRNAs for E-selectin, ICAM-1, and VCAM- 1 at 4 and $6 \mathrm{~h}$. The intensity of the signal was assessed using a phosphorimager and corrected for loading by comparison with the intensity provided by $28 \mathrm{~s}$ ribosomal RNA. 

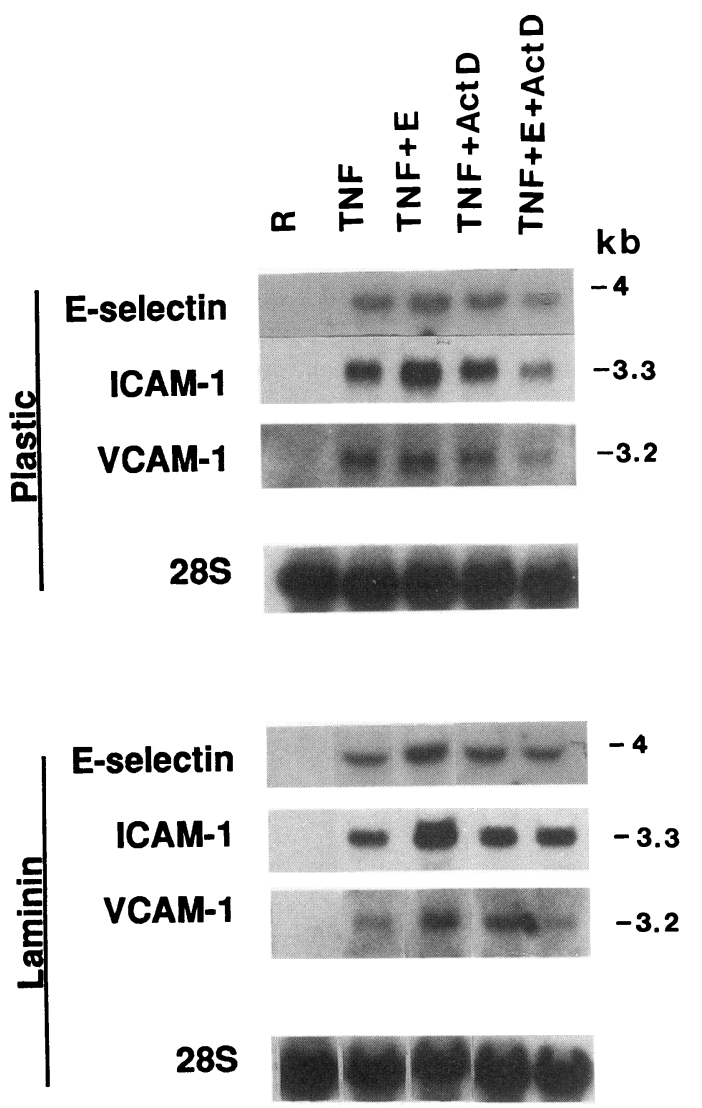

Figure 9. Effect of estradiol on mRNA levels of TNF-induced adhesion molecules E-selectin, ICAM-1, and VCAM-1. The experiment was performed on plastic and laminin. Total RNA was obtained from resting HUVEC $(R)$, TNF-stimulated HUVEC $(T N F)$, and TNF-stimulated HUVEC in the presence of $5 \mathrm{ng} / \mathrm{ml}$ estradiol after a 3-h incubation $(T N F+E)$. At the same time, RNA was obtained from TNF-stimulated HUVEC without and with estradiol pretreatment for $1 \mathrm{~h}$ before harvesting with $2 \mu \mathrm{g} / \mathrm{ml}$ actynomycin D (Act $D)$. Filters were hybridized with ICAM-1 cDNA probe and synthetic oligonucleotides encoding portions of the E-selectin and VCAM-1 sequence. The same filter was probed for 28 s ribosomal RNA.

and VCAM-1, as detected by immunofluorescence. In addition, specific antibodies to adhesion molecules partially blocked the increase in TNF-induced adhesion stimulated by estradiol. We propose that increased expression is mediated, at least in part, by a transient increase in steady-state mRNA for E-selectin, ICAM-1, and VCAM-1 that precedes the increase in protein expression. An increase is apparent at $4 \mathrm{~h}$, but by $6 \mathrm{~h}$ expression of mRNA levels for these adhesion molecules was reduced in the presence of estradiol. A similar biphasic response occurs when IFN- $\gamma$ is used to enhance TNF-induced E-selectin expression (46). Steroid hormones bind to specific receptors that are transcriptional enhancers and regulate gene expression by binding to specific DNA sequences (49). Recently, estrogens and other steroid hormones also have been shown to regulate gene expression indirectly at a posttranscriptional level by modifying the stability of certain mRNAs (50). The estradiol-enhanced decrease in steady-state expression of mRNA for adhesion molecules was accelerated when the cells were treated with actinomycin $\mathrm{D}$. These data provide evidence supporting posttranscriptional regulation of $\mathrm{mRNAs}$ for E-se- lectin, ICAM-1, and VCAM-1, and a role for estradiol in such regulation. Previous studies have shown that mRNAs particularly susceptible to such regulation by steroid hormones are those rich in AUUUA sequences in the $3^{\prime}$ untranslated region (51); such sequences are present in E-selectin, ICAM-1, and VCAM-1 (52-54).

The effects of estradiol on adhesion and on expression of adhesion molecules were greatest when the cells were plated on laminin. Estradiol has been shown to increase attachment of estrogen-dependent cancer cell lines to laminin (55), and both estradiol and progesterone increase the expression of laminin receptors $(56,57)$. In addition, we recently observed in preliminary experiments that estradiol increases expression of beta-1 integrins by endothelial cells (58). Therefore, estradiol-induced interactions with basement membrane proteins might be crucial in regulating the expression of other receptors.

In summary, our data demonstrate an important modulatory effect of estradiol on leukocyte-endothelial cell interactions mediated by TNF. This mechanism could play a role in the development and perpetuation of chronic inflammatory diseases. Such interactions are increased in the presence of estradiol and are mediated in part by increased expression of adhesion molecules on the surface of endothelial cells. ICAM-1 and VCAM-1 also play an important role as accessory molecules in immune recognition $(8,59)$. Exploring the ability of sex hormones to regulate expression of ICAM-1 and VCAM-1 in endothelial and other cell types may provide insight into the observed gender differences in autoimmune diseases.

\section{Acknowledgments}

We thank Mr. Juanjo Barceló and Dr. Odette Viñas (Immunology Department, Hospital Clínic i Provincial, Barcelona) for their advice and help in flow cytometry.

M. C. Cid was supported by grants from Fondo de Investigaciones Sanitarias de la Seguridad Social (FIS 91/ 5310 and FIS 93/0603) and by the Fogarty visiting program. H. W. Schnaper was supported by National Research Service Award DK-08712 from the National Institutes of Health and by a grant from the Children's Research Institute, Children's National Medical Center, Washington, DC.

\section{References}

1. Ahmed, S. A., W. J. Penhale, and N. Talal. 1985. Sex hormones, Immune responses, and autoimmune diseases. Mechanisms of sex hormone action. Am.J. Pathol. 121:531-551.

2. Grossman, C. 1989. Possible underlying mechanisms of sexual dimorphism in the immune response, fact and hypothesis. J. Steroid Biochem. 34:241251.

3. Lahita, R. G. 1985. Sex steroids and the rheumatic diseases. Arthritis Rheum. 28:121-126.

4. Shelhamer, J. H., D. J. Volkman, J. E. Parrillo, T. J. Lawley, M. R. Johnston, and A. S. Fauci. 1985. Takayasu's arteritis and its therapy. Ann. Intern. Med. 103:121-126.

5. Cutolo, M., E. Balleari, M. Giusti, E. Intra, and S. Accardo. 1991. Androgen replacement therapy in male patients with rheumatoid arthritis. Arthritis Rheum. 34:1-5.

6. Ahmed, S. A., M. J. Dauphinee, A. I. Montoya, and N. Talal. 1989. Estrogen induces normal murine CD5+ B cells to produce autoantibodies. J. Immunol. 142:2647-2653.

7. Okuyama, R., T. Abo, S. Seki, T. Ohteki, K. Sugiura, A. Kusumi, and K. Kumagai. 1992. Estrogen administration activates extrathymic $\mathrm{T}$ cell differentiation in the liver. J. Exp. Med. 175:661-669.

8. Springer, T. A. 1990. Adhesion receptors in the immune system. Nature (Lond.). 346:425-433.

9. Osborn, L. 1990. Leukocyte adhesion to endothelium in inflammation. Cell. 62:3-6.

10. Butcher, E. C. 1991. Leukocyte-endothelial cell recognition: three or more steps to specificity and diversity. Cell. 67:1033-1036.

11. Lorant, D. E., K. D. Patel, T. M. Mc Intyre, R. P. Mc Ever, S. M. Prescott, 
and G. A. Zimmerman. 1991. Coexpression of GMP-140 and PAF by endothelium-stimulated by histamine or thrombin: a juxtacrine system for adhesion and activation of neutrophils. J. Cell Biol. 115:223-234.

12. Albelda, S., P. D. Oliver, L. H. Romer, and C. A. Buck. 1990. Endo-CAM: a novel endothelial cell-cell adhesion molecule. J. Cell Biol. 110:1227-1237.

13. Munro. J. M.. J. S. Pober, and R. Cotran. 1989. Tumor necrosis factor and interferon gamma induce distinct patterns of endothelial activation and associated leukocyte accumulation in skin of Papio Annubis. Am. J. Pathol. 135:121133.

14. Dustin. M. L., R. Rothlein, A. K. Bhan, C. A. Dinarello, and T. A. Springer. Induction by IL- 1 and interferon gamma: tissue distribution, biochemistry and function of a natural adherence molecule (ICAM-1). 1986. J. Immunol. 137:245-254.

15. Rice. G. E., J. M. Munro. and M. P. Bevilacqua. 1990. Inducible cell adhesion molecule 110 (INCAM-110) is an endothelial receptor for lymphocytes. A CD11/CD18-independent adhesion mechanism. J. Exp. Med. 171:1391374.

16. Sollberg. S., J. Peltonen, J. Vitto, and S. Jimenez. 1992. Elevated expression of beta- 1 and beta- 2 integrins, intercellular adhesion molecule 1 in the skin of patients with systemic sclerosis of recent onset. Arthritis Rheum. 35:290-298.

17. Wawryk. S. O.. H. Ayberk. A. W. Boyd. and J. Rode. 1991. Analysis of adhesion molecules in the immunopathogenesis of giant cell arteritis. J. Clin. Pathol. 44:497-501.

18. Colburn. P., and V. Buonassisi. 1978. Estrogen-binding sites in endothelial cell cultures. Science (Wash. DC). 201:817-819.

19. Alexander. J. J., M. Hoenig. D. Graham. and A. Imbembo. 1989. Effect of estradiol on low density lipoprotein uptake by bovine aortic endothelial cells. $J$. Surg. Res. 46:537-542.

20. Campisi. D.. A. Bivona, S. Paterna, M. Valenza, and R. Albiero. 1987. Oestrogen binding sites in fresh aortic tissue. Int. J. Tissue React. 9:393-398.

21. Ingegno, M. D., S. R. Money, W. Thelmo, G. L. Greene. M. Davidian. B. M. Jaffe, and L. P. Pertschuk. 1988. Progesterone receptors in the human heart and great vessels. Lab. Invest. 59:353-356.

22. Gisclard, V., V. M. Miller, and P. M. Vanhoutte. 1988. Effect of 17-betaestradiol on endothelium-dependent responses in the rabbit. J. Pharmacol. Exp. Ther. 244:19-22.

23. Jaffe, E. A.. R. L. Nachman. C. G. Becker, and C. R. Minick. 1973. Culture of endothelial cells derived from umbilical veins. Identification by morphological and immunological criteria. J. Clin. Invest. 52:2745-2756.

24. Mc Faul, S. J. 1990. A method for isolating neutrophils from moderate volumes of human blood. J. Immunol. Methods. 130:15-18.

25. Kleinman, H. K., M. L. McGarvey, J. R. Hassell, V. L. Star, F. B. Cannon, G. W. Laurie, and G. R. Martin. 1986. Basement membrane complexes with biological activity. Biochemistry: 25:312-318.

26. Young. I. T. 1977. Proof without prejudice: use of the Kolmogorov-Smirnov test for the analysis of histograms from flow systems and other sources. $J$. Histochem. Cytochem. 25:935-941.

27. Sambrook, J.. E. F. Fritsch, and T. Maniatis. 1989. Molecular Cloning: A Laboratory manual. Cold Spring Harbor Laboratory, Cold Spring Harbor. New York. 7:19-7.22.

28. Ausubel. F. M. R. Brent. R. E. Kingston. D. D. Moore. J. G. Seideman. J. A. Smith, and K. Struhl. 1989. In Current Protocols in Molecular Biology. New York. Greene Publishing Associates and Wiley-Interscience. New York. 3.10.33.10 .5

29. Gamble, J. R., J. M. Harlan, S. J. Klebanoff, and M. A. Vadas. 1985 Stimulation of the adherence of neutrophils to umbilical vein endothelium by human recombinant tumor necrosis factor. Proc. Natl. Acad. Sci. US.A. 82:86678671 .

30. Cavender, D. E., Y. Saegusa, and M. Ziff. 1987. Stimulation of endothelial cell binding of lymphocytes by tumor necrosis factor. J. Immunol. 139:18551860 .

31. Thornhill. M. H., V. Kyan-Aung. T. H. Lee, and D. O. Haskard. 1990. T cells and neutrophils exhibit differential adhesion to cytokine-stimulated endothelial cells. Immunologl: 69:287-292.

32. Shimizu, Y., W. Newman, T. Venkat Gopal, K. J. Horgan, N. Graber L. D. Beall, G. A. van Seventer, and S. Shaw. 1991. Four molecular pathways of T cell adhesion to endothelial cells: roles of LFA-1, VCAM-1 and ELAM-1 and changes in pathway hierarchy under different activation conditions. $J$. Cell Biol. 113:1203-1212.

33. van Seventer, G. A., Y. Shimizu. and S. Shaw. 1991. Roles of multiple adhesion molecules in T-cell activation. Curr. Opin. Immunol. 3:294-303.

34. Shimizu, Y., W. Newman. Y. Tanaka, and S. Shaw. 1992. Lymphocyte interactions with endothelial cells. Immunol. Toda1: 13:106-112.

35. Pardi, R., L. Inverardi, and J. R. Bender. 1992. Regulatory mechanisms in leukocyte adhesion: flexible receptors for sophisticated travelers. Immunol. Todav: 13:224-230.

36. Zimmerman, G. A., S. M. Prescott. and T. M. Mclntyre. 1992. Endothelial cell interactions with granulocytes: tethering and signaling molecules. $\mathrm{Im}$ munol. Todal: 13:93-100.

37. Jilka. R. L.. G. Hangoc, G. Girasole, G. Passeri, D. C. Williams, J. S.
Abrams, B. Boyce. H. Broxmeyer and S. C. Manolagas. 1992. Increased osteoclast development after estrogen loss: mediation by interleukin-6. Science (Wash. DC). 257:88-91.

38. Araneo, B. A.. T. Dowell, M. Diegel, and R. A. Daynes. 1991. Dihydrotestosterone exerts a depressive influence on the production of interleukin-4 (IL-4) IL-5, and gamma-interferon, but not IL-2 by activated murine T cells. Blood. 78:688-699.

39. Daynes. R. A., D. J. Dudley, and B. A. Araneo. 1990. Regulation of murine lymphokine production in vivo. II. Dehydroepiandrosterone is a natural enhancer of interleukin 2 synthesis by helper T cells. Eur. J. Immunol. 20:793802.

40. Tabibzadeh, S. S.. U. Santhanam. P. B. Sehgal, and L. T. May. 1989. Cytokine-induced production of IFN-beta ${ }_{2} /$ IL- 6 by freshly explanted human endometrial stromal cells. Modulation by estradiol-17beta. J. Immunol. 142:3134-3139.

41. Guerne. P. A.. D. A. Carson, and M. Lotz. 1990. IL-6 production by human articular chondrocytes. Modulation of its synthesis by cytokines, growth factors. and hormones in vitro. J. Immunol. 144:499-505.

42. Roby. K. F.. and P. F. Terranova. 1990. Effects of tumor necrosis factoraipha in vitro on steroidogenesis of healthy and atretic follicles of the rat: theca as a target. Endocrinologl: 126:2711-2718.

43. Danforth. D. N., and M. K. Sgagias. 1991. IL-1 alpha blocks estradiol-stimulated growth and down-regulates the estrogen receptor in MCF-7 breast-cancer cells in vitro. Cancer Res. 51:1488-1493.

44. Pober, J.. M. A. Gimbrone. L. A. Lapierre, D. L. Mendrick, W. Fiers, R Rothlein. and T. A. Springer. 1986. Overlapping patterns of activation of human endothelial cells by interleukin 1, tumor necrosis factor, and immune interferon. J. Immunol. 137:1893-1896.

45. Thornill, M. H.. S. M. Wellicome, D. L. Mahiouz, J. S. S. Lanchbury, U. Kyan-aung. and D. O. Haskard. 1991. Tumor necrosis factor combines with IL-4 or IFN-gamma to selectively enhance endothelial cell adhesiveness for $\mathrm{T}$ cells The contribution of vascular cell adhesion molecule-1-dependent and -independent binding mechanisms. J. Immunol. 146:592-598.

46. Doukas. J., and J. S. Pober. 1990. IFN-gamma enhances endothelial activation induced by tumor necrosis factor but not IL-1. J. Immunol. 146:17271733.

47. Cronstein. B. N.. S. C. Kimmel. R. I. Levin. F. Martiniuk, and G. Weissmann. 1992. A mechanism for the antiinflammatory effects of corticosteroids the glucocorticoid receptor regulates leukocyte adhesion to endothelial cells and expression of endothelial-leukocyte adhesion molecule 1 and intercellular adhesion molecule 1. Proc. Natl. Ac'ad. Sci. LS.4. 89:9991-9995.

48. Perrot-Aplanat, M.. M. T. Groyer-Picard, E. Garcia, F. Lorenzo, and E. Milgrom. 1988. Immunocytochemical demonstration of estrogen and progesterone receptors in muscle cells of uterine arteries in rabbits and humans. Endocrinolog1: 123:1511-1519.

49. Beato, M. 1989. Gene regulation by steroid hormones. Cell. 56:335-344.

50. Carter. B. Z., and J. S. Malter. 1991. Regulation of mRNA stability and its relevance to disease. Lab. Invest. 65:610-621.

51. Peppel, K.. J. M. Vinci. and C. Baglioni. 1991. The AU-rich sequences in the $3^{\prime}$ untranslated region mediate the increased turnover of interferon mRNA induced by glucocorticoids. J. Exp. Med. 173:349-355.

52. Staunton, D. E., S. D. Martin, C. Stratowa, M. L. Dustin, and T. A. Springer. 1988. Primary structure of ICAM-1 demonstrates interaction between members of the immunoglobulin and integrin supergene families. Cell. 52:925933.

53. Osborn, L., C. Hession. R. Tizard, C. Vassallo, S. Luhowskyj, G. ChiRosso, and R. Lobb. 1989. Direct expression cloning of vascular cell adhesion molecule 1 , a cytokine-induced endothelial protein that binds to lymphocytes. Cell. 59:1203-1211.

54. Hession, C., L. Osborn, D. Goff, G. Chi-Rosso, C. Vassallo, M. Pasek, C. Pittack, R. Tizard, S. Goelz. K. Mc Carthy, S. Hopple, and R. Lobb. 1990. Endothelial leukocyte adhesion molecule-1: direct expression cloning and functional interactions. Proc. Natl. Acad. Sci. USA. 87:1673-1677.

55. Albini, A.. J. Graf, G. T. Kitten, H. K. Kleinman. G. R. Martin, A Veillette, and M. E. Lippman. 1986. 17beta-estradiol regulates and v-Ha-ras transfection constitutively enhances MCF7 breast cancer cell interactions with basement membrane. Proc. Natl. Acad. Sci. USA. 83:8182-8186.

56. Shi. Y. E., J. Torri, M. E. Sobel. Y. Yamada, M. E. Lippman. R. B. Dickson. and $\mathrm{R}$. Thompson. 1991. Regulation of laminin receptors by progestin in T47D human breast cancer cells. Proc. Am. Assoc. Cancer Res. 32:66.

57. van der Brule. F. A.. J. Engel. W. G. Stetler-Stevenson. F. T. Liu. M. E. Sobel, and V. Castronovo. 1992. Genes involved in tumor invasion and metastasis are differentially modulated by estradiol and progestin in human breast-cancer cells. Int. J. Cancer. 52:653-657.

58. Cid. M. C., H. K. Kleinman, D. S. Grant. A. S. Fauci, and G. S. Hoffman. 1991. Estradiol increases leukocyte adhesion to TNF-stimulated HUVEC. Implications for the pathogenesis of Takayasu's arteritis. Arthritis Rheum. 34:S169.

59. Damle. N. K.. and A. Aruffo. 1991. Vascular cell adhesion molecule 1 induces $\mathrm{T}$-cell antigen receptor-dependent activation of $\mathrm{CD}^{+}{ }^{+} \mathrm{T}$ lymphocytes. Proc. Natl. Acad. Sci. US.1. 88:6403-6407. 